\title{
DIAGNOSTIC ACCURACY OF MAMMOGRAPHY AND ULTRASONOGRAPHY FOR BREAST DISEASES
}

\author{
Rajesh Chakkarapani1 ${ }^{1}$ Balaji Durairaj ${ }^{2}$
}

${ }_{1}^{1}$ Assistant Professor, Department of General Surgery, SRM Medical College Hospital and Research Centre, Kattankulathur, Kanchipuram.

${ }^{2}$ Assistant Professor, Department of General Surgery, SRM Medical College Hospital and Research Centre, Kattankulathur, Kanchipuram.

\section{ABSTRACT}

\section{BACKGROUND}

Detecting the breast pathologies, at its earliest possible stage is the ultimate goal in imaging the breast. Diagnosis chiefly includes radiological investigations like mammography and ultrasonography followed by biopsy. The incidence of breast cancer deaths can be reduced by $30 \%$ by the routine screening of healthy women with mammography. USG plays a key role in differentiating solid and cystic masses. It is useful in the evaluation of palpable masses not visible radiographically.

The purpose of this study was to compare the role of mammography and ultrasonography in the evaluation of breast diseases and to compare the diagnostic accuracy of ultrasonography and mammography for diagnosing breast diseases when doing individually and its combination on same patients.

\section{MATERIALS AND METHODS}

Data for this descriptive study were sourced from all female patients above 15 years of age who presented with symptoms of breast diseases like breast lump, pain in the breast and nipple discharge to outpatient and inpatient surgery department in SRM Medical College Hospital and Research Centre, Kattankulathur during the period from June 2013 to May 2016. Data collection methods include direct interview, clinical examination, mammography and ultrasonogram of symptomatic breast followed by FNAC (Fine Needle Aspiration Cytology) in all patients and excision biopsy in selected cases. Then the reports of FNAC/histopathological examinations were compared with the results of mammography and ultrasonogram of breast.

\section{RESULTS}

According to this study, MG showed a sensitivity of $82.6 \%$ compared to $73.9 \%$ for USG in detecting fibroadenoma. However, their combined approach resulted in $95.7 \%$. In case of fibrocystic disease MG showed $27.6 \%$ and USG only $75.9 \%$ and the combination resulted in $75.9 \%$. For diagnosing carcinomas MG had a sensitivity of $83.3 \%$ and USG $73.3 \%$, but the combination had an efficiency of $100 \%$. Overall, the histopathological results when correlated with each modality finding showed that MG had an efficiency of only $61.3 \%$ and USG only $77.4 \%$ when used alone in detecting these lesions of the breast compared to an efficiency of $91.2 \%$ obtained by their combined approach. Positive predictive value of ultrasonogram and mammogram was $98.6 \%$ and $100 \%$ respectively. Negative predictive value for USG and MG was $22.2 \%$ and $15.2 \%$ respectively with the accuracy rate of $78 \%$ for USG and $61 \%$ for MG.

\section{CONCLUSION}

Mammogram and ultrasonogram are two important non-invasive investigations available for evaluating breast diseases. Mammogram is more efficient in diagnosing malignant diseases of the breast, while ultrasonogram is more efficient in diagnosing benign breast diseases. The combinations of ultrasonogram and mammogram will diagnose almost all diseases of the breast. By using these non-invasive diagnostic modality, unnecessary invasive procedures like FNAC biopsy can be avoided.

\section{KEYWORDS}

Mammography, Ultrasonography, FNAC, Breast Cancer, Breast Evaluation.

HOW TO CITE THIS ARTICLE: Chakkarapani R, Durairaj B. Diagnostic accuracy of mammography and ultrasonography for breast diseases. J. Evolution Med. Dent. Sci. 2018;7(05):592-596, DOI: 10.14260/jemds/2018/135

\section{BACKGROUND}

Detecting the breast pathologies, at its earliest possible stage is the ultimate goal in imaging the breast. Diagnosis chiefly includes radiological investigations like mammography and ultrasonography followed by biopsy. The incidence of breast cancer deaths can be reduced by $30 \%$ by the routine screening of healthy women with mammography.

'Financial or Other Competing Interest': None.

Submission 20-12-2017, Peer Review 13-01-2018,

Acceptance 19-01-2018, Published 29-01-2018.

Corresponding Author:

Dr. Rajesh Chakkarapani,

No. 5/3, Muthu Street Krishnapuram,

Gingee-604202, Villupuram District.

E-mail: drrajesh83@gmail.com

DOI: $10.14260 /$ jemds $/ 2018 / 135$
This is because breast changes like asymmetry, neodensity, distortion of fibroglandular architecture and microcalcifications are picked up earlier than lesions that become clinically palpable or are sometime detected by self examination.1,2 USG plays a key role in differentiating solid and cystic masses. It is useful in the evaluation of palpable masses not visible radiographically; dense breasts, abscesses and masses that are not completely evaluable with mammogram and in young patients susceptible to radiation damage. Both mammogram and ultrasonogram methods have been used in attempts to reduce the negative-to-positive biopsy ratio. ${ }^{3}$

\section{Objectives of the Study}

To compare the diagnostic accuracy of mammography and ultrasonography for various breast diseases when doing independently and its combination. 


\section{MATERIALS AND METHODS}

Data for this descriptive study was sourced from hundred female patients above 15 yrs. of age who presented with breast lump, pain in the breast and nipple discharge and willing to undergo mammogram, ultrasonogram and treatment for their breast disease in outpatient and inpatient surgery department in SRM Medical College Hospital and Research Centre, Kattankulathur during the period from June 2013 to May 2016 were included as study subjects. Patients with recurrent breast lumps and postoperative case of breast diseases were excluded. After taking the informed consent, data was collected by direct interview. Clinical examination of all systems and local examination of breast and then all patients were subjected to mammogram and ultrasonogram of symptomatic breast. Patients were then subjected to FNAC (Fine Needle Aspiration Cytology) followed by excision biopsy in selected cases. Then the reports of FNAC/Histopathological examinations (Gold Standard) were compared with the results of mammography and ultrasonogram of breast. Data analysis was done using SPSS 16.0 version. Descriptive statistics were calculated in percentages. Sensitivity, specificity, positive predictive value and negative predictive value were expressed as percentages.

\section{RESULTS}

Based on the histopathology report, 93 patients were found to be suffering from breast diseases. Ductal carcinoma, fibrocystic diseases, fibroadenoma and mastitis were reported in 30 patients, 29 patients, 23 patients and 9 patients respectively. Also, galactocoele and lactational adenoma was reported in one patient each. Out of the 93 female participants with breast diseases the sensitivity of ultrasonogram was found to be $73.9 \%, 73.3 \%$ and $75.8 \%$ in finding fibroadenoma, ductal carcinoma and fibrocystic diseases, respectively. Also $100 \%$ sensitivity was found in galactocele, lactational adenoma and mastitis. Sensitivity of mammogram was found to be $82.6 \%, 83.3 \%, 27.5 \%$ and
$22.2 \%$ in finding fibroadenoma, ductal carcinoma, fibrocystic diseases and mastitis respectively. Sensitivity of combining ultrasonogram and mammography was found to be $95.7 \%$ and $75.9 \%$ in finding fibroadenoma and fibrocystic diseases, respectively. Also $100 \%$ sensitivity was found in ductal carcinoma, galactocoele, lactational adenoma and mastitis (Table 1).

\begin{tabular}{|c|c|c|c|c|c|c|c|}
\hline 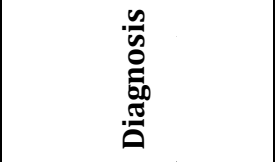 & $\underset{\overparen{\pi}}{\stackrel{7}{0}}$ & $\stackrel{5}{\mathscr{b}}$ & 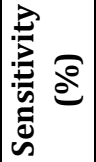 & $\stackrel{5}{\Sigma}$ & 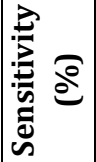 & 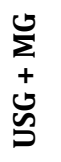 & 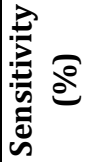 \\
\hline Fibroadenoma & 23 & 17 & 73.9 & 19 & 82.6 & 22 & 95.7 \\
\hline Ductal Carcinoma & 30 & 22 & 73.3 & 25 & 83.3 & 30 & 100 \\
\hline Fibrocystic Disease & 29 & 22 & 75.8 & 8 & 27.5 & 22 & 75.9 \\
\hline Galactocele & 1 & 1 & 100 & 0 & 0 & 1 & 100 \\
\hline $\begin{array}{c}\text { Lactational } \\
\text { Adenoma }\end{array}$ & 1 & 1 & 100 & 0 & 0 & 1 & 100 \\
\hline Mastitis & 9 & 9 & 100 & 2 & 22.2 & 9 & 100 \\
\hline Total & 93 & 72 & 77.4 & 54 & 58.06 & 85 & 91.4 \\
\hline \multicolumn{8}{|c|}{$\begin{array}{c}\text { Table 1. Ultrasonogram and Mammogram Diagnoses in } \\
\text { various Breast Diseases }\end{array}$} \\
\hline
\end{tabular}

Ultrasonogram detects the lesion by the features of shape, margin, echogenicity, homogenicity, compressibility, posterior enhancement and calcifications. Ultrasonogram clearly differentiate carcinoma from benign disease with the features of irregular margin and shape, anechoic or mixed echogenicity and distorted architecture of surrounding breast parenchyma and evidence of microcalcification noted. The real advantage of USG was that solid and cystic masses could be differentiated well and young breasts with dense fibroglandular parenchyma could be imaged with ease. Number of cases with specific USG findings were given in Table 2 .

\begin{tabular}{|c|c|c|c|c|c|c|}
\hline HPR & Fibroadenoma & $\begin{array}{c}\text { Fibrocystic } \\
\text { Disease }\end{array}$ & Mastitis & Carcinoma & Galactocele & $\begin{array}{c}\text { Lactational } \\
\text { Adenoma }\end{array}$ \\
\hline $\begin{array}{l}\text { No. of Cases } \\
\text { Diagnosed }\end{array}$ & 17 & 22 & 9 & 22 & 1 & 1 \\
\hline Shape & Oval (17) & $\begin{array}{l}\text { Irregular (20) } \\
\text { Diffuse (2) }\end{array}$ & $\begin{array}{c}\text { Oval (7) } \\
\text { Irregular (2) }\end{array}$ & Irregular (22) & Irregular (1) & Oval (1) \\
\hline Margin & Round (17) & Irregular (22) & $\begin{array}{l}\text { Irregular (2) } \\
\text { Round (7) }\end{array}$ & Irregular (22) & Round (1) & Round (1) \\
\hline Echogenicity & Hypoechoic (17) & Hypoechoic (21) & Hypoechoic (7) & $\begin{array}{c}\text { Anechoic (6) } \\
\text { Mixed Echogenicity (16) }\end{array}$ & $\begin{array}{l}\text { Hypoechoic } \\
\text { (1) }\end{array}$ & $\begin{array}{c}\text { Hypoechoic } \\
\text { (1) }\end{array}$ \\
\hline Calcification & Coarse Cal+ (3) & - & - & Microcal + (16) & - & 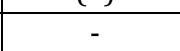 \\
\hline Homogenicity & Uniform (17) & $\begin{array}{l}\text { Uniform (6) } \\
\text { Mixed (16) }\end{array}$ & Uniform (7) & Mixed (22) & Uniform (1) & Uniform (1) \\
\hline Compressibility & No & No & Yes & No & Yes & No \\
\hline $\begin{array}{c}\text { Posterior } \\
\text { Enhancement }\end{array}$ & Yes & No & Yes & No & No & Yes \\
\hline
\end{tabular}

According to mammogram, the lesions were analysed on the basis of their location (relation to their quadrant), number of asymmetrical lesions, well defined or merging with the adjacent normal breast tissue, density of the lesion, margins, surrounding halo, the presence or absence of intramammary and axillary lesions, classified according to BIRADS classification. Number of cases with specific MG findings were given in Table 3. 


\begin{tabular}{|c|c|c|c|c|}
\hline HPR & Fibroadenoma & Fibrocystic Disease & Mastitis & Carcinoma \\
\hline Number of Cases & 19 & 8 & 2 & 25 \\
\hline Density & Increased (19) & Increased (8) & Increased (2) & Increased (25) \\
\hline Margin & Round (19) & Irregular (8) & Irregular (1) Round (1) & Irregular (25) \\
\hline Calcification & Coarse Cal+(3) & - & - & Microcal+(23) \\
\hline Architecture & Normal & Normal & Normal & Asymmetrical (17) \\
\hline Fibroglandular & Normal & Normal & Normal & Normal \\
\hline Skin Thickness & Normal & Normal & Normal & Increased (2) \\
\hline BIRADS & 2 & 2 & 4,5 \\
\hline
\end{tabular}

According to this study, MG had a sensitivity of $27.6 \%$ compared to $75.9 \%$ for USG for detecting fibrocystic disease, but their combined approach resulted in $75.9 \%$. In diagnosing fibroadenomas, MG showed $82.6 \%$ sensitivity and USG $73.9 \%$ and the combination $95.7 \%$. For carcinomas, MG had a sensitivity of $83.3 \%$ and USG $73.3 \%$, but the combination had a sensitivity of $100 \%$.

\begin{tabular}{|c|c|c|c|}
\hline USG & $\begin{array}{c}\text { Disease } \\
\text { Present }\end{array}$ & $\begin{array}{c}\text { Disease } \\
\text { Absent }\end{array}$ & Total \\
\hline Positive & 72 & 01 & 73 \\
\hline Negative & 21 & 06 & 27 \\
\hline Total & 93 & 07 & 100 \\
\hline \multicolumn{3}{|r|}{$\begin{array}{l}\text { Table 4. Diagnostic Accuracy of USG in } \\
\text { Detecting all Breast Diseases }\end{array}$} \\
\hline
\end{tabular}

Sensitivity $=77.4(67.9-84.7)$

Specificity $=85.7(48.7-97.4)$

$\mathrm{PPV}=98.6(92.6-99.7)$

$\mathrm{NPV}=22.2(10.6-40.7)$

Efficiency $=78(68.9-85.0)$

\begin{tabular}{|c|c|c|c|}
\hline MMG & $\begin{array}{c}\text { Disease } \\
\text { Present }\end{array}$ & $\begin{array}{c}\text { Disease } \\
\text { Absent }\end{array}$ & Total \\
\hline Positive & 54 & 00 & 54 \\
\hline Negative & 39 & 07 & 46 \\
\hline Total & 93 & 07 & 100 \\
\hline \multicolumn{4}{|c|}{ Table 5. Diagnostic Accuracy of Mammography in } \\
Detecting all Breast Diseases \\
\hline
\end{tabular}

Sensitivity $=58.06(47.7-67.8)$

Specificity $=100(64.6-100)$

$\mathrm{PPV}=100(93.4-100)$

$\mathrm{NPV}=15.2(7.6-28.2)$

Efficiency $=61(51.2-69.9)$

Overall, the histopathological results when correlated with each modality findings revealed that $M G$ had a sensitivity of $61.3 \%$ and USG $77.4 \%$ when used alone in detecting these lesions of the breast compared to a sensitivity of $91.2 \%$ obtained by their combined approach. The ultrasonogram had a specificity of $85.7 \%$, whereas mammogram had a specificity of $100 \%$. It means false positive was 0 in our study. Positive predictive value of ultrasonogram and mammogram was $98.6 \%$ and $100 \%$ respectively. Negative predictive value for USG and MG was $22.2 \%$ and $15.2 \%$ respectively with the accuracy rate of $78 \%$ for USG and $61 \%$ for MG.

This study showed that there was no significant difference in sensitivity between MG and USG in case of fibroadenoma $(p=0.72)$ and carcinoma $(p=0.53)$, but there was a significant difference between MG and USG in case of fibrocystic disease $(p=0.001)$.

There was a significant difference between when USG alone and combination of USG and MG in case of carcinoma $(p=0.005)$. Similarly, significant difference present when doing MG alone and combination of MG and USG in case of fibrocystic diseases $(p=0.001)$.

\begin{tabular}{|c|c|c|c|c|c|c|c|}
\hline \multicolumn{7}{|c|}{ Number of Cases } & \multicolumn{4}{c|}{ P value } \\
\hline Diagnosis & FNAC & USG & MG & $\begin{array}{c}\text { USG+ } \\
\text { MG }\end{array}$ & $\begin{array}{c}\text { USG } \\
\text { and MG }\end{array}$ & $\begin{array}{c}\text { USG and } \\
\text { USG+MG }\end{array}$ & $\begin{array}{c}\text { MG and } \\
\text { USG+MG }\end{array}$ \\
\hline Fibroadenoma & 23 & 17 & 19 & 22 & 0.72 & 0.10 & 0.34 \\
\hline $\begin{array}{c}\text { Ductal } \\
\text { Carcinoma }\end{array}$ & 30 & 22 & 25 & 30 & 0.53 & $0.005^{*}$ & 0.052 \\
\hline $\begin{array}{c}\text { Fibrocystic } \\
\text { Disease }\end{array}$ & 29 & 22 & 8 & 22 & 0.001 & 1.0 & $0.001^{*}$ \\
\hline \multicolumn{7}{|c|}{ Table 6. Statistical Evaluation of } \\
USG/Mammography/FNAC in Detecting Breast Diseases \\
\hline
\end{tabular}

Fisher's exact test *statistically significant.

\section{DISCUSSION}

Breast cancer is one of the most prevalent cancers in the world among women and is the second most common cancer in Indian women. Of all breast disorders, palpable breast lump is the second most common presentation, pain being the first.

Breast problem could be as simple as breast abscess to as ominous as cancer. ${ }^{4}$ The breast lump besides creating anxiety may result in carcinoma and causes unbearable pain and deformity. Benign breast disease is so common that over half of the female population at some time in life seeks medical advice for breast problem, but effective evaluation and prompt diagnosis was needed to rule out malignancy. An early accurate diagnosis of breast disease has a favourable prognosis than that of late detection. ${ }^{5}$

For evaluation of breast disease, the most common imaging modality ultrasonography and mammography are used. Both have been used in an attempt to reduce the negative to positive biopsy ratio. The spectrum of breast diseases is different in young females and what brings a young girl to a doctor is no more than Anomaly of Normal Breast Development and Involution (ANDI). The term ANDI implies that most breast disorders are only physiological extremes. Both ultrasonography and mammography can reduce the unnecessary invasive procedure for most of the benign breast diseases in young women. ${ }^{6}$

Mammography, the primary method of detection and diagnosis of breast disease has a proven sensitivity of $85 \%$ 95\%. In our study, the sensitivity of mammography for carcinoma is $83.3 \%$. Breast lump whether symptomatic or 
asymptomatic are frequently diagnosed by mammography. High quality mammogram screening can be considered a major public health achievement, as it reveals the various types of lesions in the breast apart from assessing the breast density. Mammography is, therefore, the gold standard for early detection of breast cancer. ${ }^{7}$

Ultrasonography (USG) is the ideal imaging modality and can be useful in identifying and characterising breast masses by certain criteria and then guiding further investigations. Ultrasonography is of great value for breast disease detection in young. Previously, the use of ultrasonography was restricted to differentiation of cystic and solid masses. Today, ultrasonography can be used to further characterise a lesion and to guide interventional procedures. In addition, the roles of ultrasonography in differentiating benign and malignant lesions are excellent. Because of the easy availability of ultrasonogram, it is considered as one of the best noninvasive investigations for evaluating breast diseases. ${ }^{8}$

Ultrasonography often detects cysts or solid lesions that are obscured on the mammogram by the surrounding fibroglandular tissue and can reduce the number of surgical biopsies required when cysts are identified. Sonographic findings can often confirm a cancer that is obscured mammographically by dense breast tissue. Sonographic technology for breast imaging has dramatically improved in the last decade. With further improvements in sonographic technology and careful prospective real-time evaluation of palpable breast lumps, perhaps the negative predictive value will one day approach $100 \%$, ideally providing complete confidence for follow-up rather than recommending biopsy of these lesions. ${ }^{9}$

Study done by Varela et $\mathrm{al}^{10}$ was able to show the various impact of different approaches used, such that mammography was capable of detecting $94.5 \%$ of breast carcinomas; breast sonography detects $91 \%$ and palpation detects $87 \%$. However, combinations of these approaches such as mammography and sonography or mammography and palpation detected $99 \%$ of carcinomas, while sonography and palpation detected $95 \%$ of carcinomas. Nevertheless, ultrasound is significantly more accurate in determining tumour size. 11

A study done by Sachin Prasad N and Dana Houserkova 12 in 2007 showed that mammography had a sensitivity of $82 \%$ for fibrocystic disease detected, 18 cases out of 22. Our study showed sensitivity of $27.5 \%$ detected, 8 cases out of 29 , remaining 21 cases were missed in mammography. In our study most of the patients diagnosed of fibrocystic disease are in the younger age group, hence dense fibroglandular breast had less sensitivity to mammogram.

Mammography is most sensitive for carcinoma. Sachin N study diagnosed 7 cases out of 9 , which showed sensitivity of $77 \%$. Similarly, our study also showed higher sensitivity of 83.3\% for carcinoma diagnosed, 25 cases out of total 30 . The high sensitivity of mammogram to carcinoma was due to its characteristic microcalcification, spiculation and architectural distortion. Hence, it can diagnose non-palpable carcinoma even in asymptomatic women. ${ }^{13}$ For fibroadenoma, the sensitivity was about $75 \%$ in Sachin Prasad N study who detected 12 cases out of 16 . In our study the detection rate was $82.6 \%, 19$ cases detected out of 23. Mammography had high sensitivity for fibroadenoma because of its characteristic appearance like well-defined borders and increased density with normal surrounding parenchyma. Mammogram had low sensitivity for mastitis, because of its diffuse location and illdefined margin sometime mimic carcinoma. ${ }^{14}$

Similarly, ultrasonogram shows $95 \%$ sensitivity for fibrocystic disease, whereas our study shows only $75.9 \%$ sensitivity. For mastitis, the sensitivity is $100 \%$ in both studies. Mastitis was characterised by irregular borders, homogenously hypoechoic with internal septations and moving debris. In our study, USG had a higher sensitivity for fibroadenoma, i.e. 73.9\% compared to that of Sachin Prasad N (31\%). Detection of malignancy when doing USG alone is $55 \%$, whereas our study shows $73.3 \%$. When doing USG alone for breast diseases, it had a high sensitivity for infective pathology (mastitis) but had a low detection rate for carcinoma. The variations in the sensitivity may be due to operator dependence of the ultrasonogram. ${ }^{15}$

The sensitivity for diagnosing both benign and malignant diseases was very high in case of combined modality of both ultrasonogram and mammogram in the same patients than doing either of the one alone. For example, in case of carcinoma the sensitivity for ultrasonogram was $73.3 \%$ and for mammogram alone was $83.3 \%$, but the combined sensitivity was $100 \%$. This was due to cases that were missed by mammogram were picked up by ultrasonogram or cases missed by ultrasonogram were picked up by mammogram, thus the combined sensitivity showed high when compared to the individual sensitivity. ${ }^{12}$

The sensitivity and specificity for benign and malignant disease when doing ultrasonogram alone in different studies were shown in the table. The sensitivity of ultrasonogram for carcinoma in all studies were high when compared to our studies. This may be due to the fact that ultrasonogram was operator dependent, but when it was done by experienced radiologist it increases both the sensitivity and specificity. Similarly, for benign disease shows high sensitivity in other studies and also in our study. ${ }^{16}$

Mammogram can help the surgeon to determine whether a lesion is potentially malignant and also screen for occult disease in the surrounding tissue. Radio-opaque ball bearings mark the location of the mass and spot compression and magnification views can clarify the breast mass and determine its density. ${ }^{17}$ If old films are available, they are compared with the new images. USG can effectively distinguish solid masses from cysts, which account for approximately 25 percent of breast lesions. When strict criteria for cyst diagnosis are met, USG has a sensitivity of 89 percent and a specificity of 78 percent in detecting abnormalities in symptomatic women. Recurrent or complex cysts may signal malignancy; therefore, further evaluation of these lesions is required. Although, USG is not considered a screening test, it is more sensitive than mammogram in detecting lesions in women with dense breast tissue. ${ }^{18}$ It is useful in discriminating between benign and malignant solid masses and it is superior to mammogram in diagnosing clinically benign palpable masses. ${ }^{14}$ It was found from the literatures that MG is a well-established diagnostic modality for the breast. MG when combined with USG can yield significant improvement in accuracy rates. ${ }^{19}$ 


\section{CONCLUSION}

Mammogram and ultrasonogram are two important noninvasive investigations available for evaluating breast diseases. Mammogram is more efficient in diagnosing malignant diseases of the breast, whereas Ultrasonogram is more efficient in diagnosing benign breast diseases. The combinations of ultrasonogram and mammogram will diagnose almost all diseases of the breast. By using these noninvasive diagnostic modality unnecessary invasive procedures like FNAC biopsy can be avoided. Both ultrasonogram and mammogram can be repeated in case of patients having persistent symptoms of breast diseases. Hence, ultrasonogram and mammogram should be used for confirming the clinical diagnosis of the breast diseases and they can be gold standard investigations for breast diseases in future days.

\section{REFERENCES}

[1] Morris KT, Vetto JT, Petty JK, et al. A new score for the evaluation of palpable breast masses in women under age 40. Am J Surg 2002;184(4):346-7.

[2] Berg WA, Gutierrez L, NessAiver MS, et al. Diagnostic accuracy of mammography, clinical examination, US, and MR imaging in preoperative assessment of breast cancer. Radiology 2004;233(3):830-49.

[3] Kerlikowske K, Smith-Bindman R, Ljung BM, et al. Evaluation of abnormal mammography results and palpable breast abnormalities. Ann Intern Med 2003;139(4):274-84.

[4] Cardenosa G. Breast imaging companion. Philadelphia, PA: Lippincott-Raven 1997.

[5] Sickles EA. Management of probably benign breast lesions. Radiol Clin North Am 1995;33(6):1123-30.

[6] Madjar H, Sauerbrei W, Prompeler HJ, et al. Colour Doppler and duplex flow analysis for classification of breast lesions. Gynaecol Oncol 1997;64(3):392-403.

[7] Morris EA. Breast cancer imaging with MRL. Radiol Clin North Am2002;40(3):443-86.

[8] Lam WW, Chu WC, Tse GM, et al. Sonographic appearance of mucinous carcinoma of the breast. Am J Roentgenol 2004;182(4):1069-74.

[9] Kopans D. Breast imaging. 2nd edn. Philadelphia: Lippincott Williams \& Wilkins 1998:29-54.
[10] Pande AR, Lohani B, Sayami P, et al. Predictive value of ultrasonography in the diagnosis of palpable breast lump. Kathmandu Univ Med J (KUMJ) 2003;1(2):78-84.

[11] Fajardo LL. Screening mammography, sonography of dense fibrocystic breast tissue. AJR Am J Roentgenol 2003;181(6):1715.

[12] Prasad SN, Houserkova D. Comparison of mammography and ultrasonography in the evaluation of breast masses. Biomed Pap Med Far Univ Palacky Olomouc Czech Repub 2007;151(2):315-22.

[13] Shetty MK, Shah YP, Sharman RS. Prospective evaluation of the value of combined mammographic and sonographic assessment in patients with palpable abnormalities of the breast. J Ultrasound Med 2003;22(3):263-8.

[14] Barton MB, Harris R, Fletcher SW. The rational clinical examination. Does this patient have breast cancer? The screening clinical breast examination: should it be done? How? JAMA 1999;282(13):127080.

[15] Osuch JR, Reeves MJ, Pathak DR, et al. BREASTAID: clinical results from early development of a clinical decision rule for palpable solid breast masses. Ann Surg 2003;238(5):728-37.

[16] Kumle M, Weiderpass E, Braaten T, et al. Use of oral contraceptives and breast cancer risk: The Norwegian-Swedish Women's Lifestyle and Health Cohort Study. Cancer Epidemiol Biomarkers Prev 2002;11(11):1375-81.

[17] Budai B, Szamel I, Sulyok Z, et al. Characteristics of cystic breast disease with special regard to breast cancer development. Anticancer Res 2001;21(1B):749-52.

[18] Barlow WE, Lehman CD, Zheng Y, et al. Performance of diagnostic mammography for women with signs or symptoms of breast cancer. J Natl Cancer Inst 2002;94(15):1151-9.

[19] Westenend PJ, Sever AR, Beekman-De Volder HJ, et al. A comparison of aspiration cytology and core needle biopsy in the evaluation of breast lesions. Cancer 2001;93(2):146-50. 